\title{
CULTIVATING INNOVATIVE TEEN-LEADERSHIP PROGRAMMING: BUILDING EVIDENCE OF IMPACT
}

\section{Abstract}

The Teen Excellence in Leadership Institute (TELI) was created to provide meaningful leadership and civicengagement experiences to teens. We integrated Chickering's Theory of Identity Development and the 4-H Citizenship Framework to develop program objectives and a model, consisting of four components: understanding of self, developing a network, community problem solving, and advocacy. This study aimed to determine the overall effectiveness of the program, highlight areas for program improvement, and provide a proof of concept for the model. Results on select 4-H Citizenship Common Measures indicated statistically significant gains in the four components of the model for cohorts one and two. Focus group data revealed five themes: diversity, connection, skill development, practical application, and learning about self. Evaluative results substantiate program impact and areas for continued program development.

\section{Introduction}

As their environments are constantly changing around them, adolescents are consistently met with various constraints and threats during this key developmental stage. Additionally, future employers continue to call for youth to develop career-readiness skills to be successful in the workforce (Crawford, Lang, Fink, \& Dalton, 2011). Youth programming has the capacity to provide career-readiness skills by supporting youth through positive youth development (PYD) (Larson, 2006; Lerner, Almerigi, Theokas, \& Lerner, 2005). Youth programming can also bolster leadership, communication, problem solving, and decisionmaking skills, which are all crucial skills to foster workforce readiness (Rutherford, Stedman, Felton, Wingenbach, \& Harlen, 2004).

Youth-leadership development is a proven strategy for aiding youth in overcoming obstacles and increasing independence, mastery, generosity, and a sense of belonging (Worker, 2014). However, intentionality of youth-leadership program models is essential to their success and the overall promotion of PYD and careerreadiness skill advancement. Various organizations around the world provide these types of programs. 4-H and the National FFA Organization (FFA, formerly the Future Farmers of America) are well-known and have a long history of providing beneficial experiences for youth and adolescents, alike (Radhakrishna \& Sinasky, 2005).

Priority One: Teaching, Learning, and Curriculum Development of the National Leadership Research Agenda (Andenoro et al., 2013) called for the exploration of innovative curriculum development frameworks. The 4- $\mathrm{H}$ administration in Virginia tasked a committee with creating a novel leadership program 
design for students in 4-H and FFA. The Teen Excellence in Leadership Institute (TELI) was the result. This program integrated the Chickering Model of Identity development (as used by National FFA), the 4-H Citizenship Framework, and a variety of other leadership-based literature with the intent to create an impactful experience for teen participants. This evaluation aimed to determine the overall effectiveness of TELI in meeting the program goals, highlighting areas for program improvement, and providing a proof of concept for the developed model. For an ongoing program, continual evaluation aids in highlighting areas for development and improvement of created program models and program designs. Furthermore, a combination of public and private funding funded the program, and evaluation offered a means for gathering and conveying feedback on the program to multiple stakeholders.

\section{Teen Excellence in Leadership Institute (TELI) Design}

TELI incorporates two face-to-face, weekend-long sessions, two virtual meetings, and a mentored small group project within the curriculum. Participants are nominated by their 4-H agent or FFA advisor and complete an application process. Using a criterion-based rubric, the selection committee reviewed applications and successful applicants were extended an offer to participate in the program. Topics covered included: Strengths-based leadership, problem-solving style, group facilitation skills, youth-adult partnerships, team building, project collaboration, peer feedback and evaluation, effective communication, leadership principles, etiquette, civic-change initiatives, and critical reflection. Youth participants engage in a team project to design a response to a community-based issue in Virginia.

The first in-person session includes team-building activities, assessments, and group formation processes designed to prepare the participants for group project work to be completed during the course of the program. The virtual sessions reinforced in-person content delivery and provided a venue for teams to share group project work and offer continued interaction between the face-toface sessions. During the closing session, teams present their projects, reflect on learning and skill development over the course of the program, make connections for transferability of skills, develop a personalized action plan for engaged leadership, and complete evaluations.

\section{Literature Review}

With PYD and career-readiness as foundational program aims, the TELI model is supported by both PYD and community youth development literature. PYD encourages advancement of strengths, talents, interests, and the future potential of all youth (Damon, 2004). Engaging programs and experiences support the promotion of the Five Cs of PYD: competence, confidence, character, connection, and caring (Lerner et al., 2005). Putting youth on a path to experience these Five Cs often culminates in thriving youth and participation in a "sixth C", contribution (Jelicic, Bobek, Phelps, Lerner, \& Lerner, 2007). Youth who thrive often participate in civic endeavors through contributions to family, community, self, and civil society as a whole (Lerner, Dowling, \& Anderson, 2003). In addition to promoting civic engagement, PYD constructs frequently reduce adolescent risk behaviors, including sexual deviance, drug use, and self-harm (Shek \& Sun, 2015).

Community youth development spans beyond personal development and involves a mutually beneficial relationship between youth and their communities. Perkins, Borden, Keith, Hoppe-Rooney, and Villarruel (2003) define community youth development as:

Purposely creating environments that provide 
encouraging relationships that are sustained over time with adults and peers, while concurrently providing an array of opportunities that enable youth to build their competencies and become engaged as partners in their own development as well as the development of communities. (p. 6)

This framework incorporates the importance of personal agency that can be defined as "one's capability to originate and direct actions for given purposes" (Zimmerman \& Cleary, 2006, p. 45). Community youth development promotes the adolescent's role in their development of interpersonal skills, which are necessary for success in the workforce. An environment which fosters this growth can be provided through community organizations that incorporate community-based principles and positive mentoring with supportive, meaningful relationships with adults (Villarruel, Perkins, Borden, \& Keith, 2003).

Many youth organizations aim to prevent negative behaviors. However, it is important to remember that ending or preventing a negative or risky behavior does not always guarantee positive benefits for the adolescents involved because the motivation to stop a behavior must be intrinsic (Larson, 2000). Damon (2004) posits that youth programs and interventions should "manifest potentialities rather than the supposed incapacities of young people" (pg. 15). By focusing on promoting self-regulatory and goal-oriented actions, problematic behavior conversely decreases (Gestsdóttir \& Lerner, 2007). Ultimately, adolescents need opportunities to harness their strengths and personal development for community advocacy, and communities need to treat and view adolescents as resources.

\section{Creation of the Model}

Through design, TELI provides opportunities for teens to develop leadership and career-readiness skills. TELI aims to promote PYD and community youth development and engages outstanding teens in a variety of programming activities through two face-to-face weekend sessions and two interactive virtual sessions. Youth participants work on a team-based project to identify and address issues that face their communities today. This experience incorporates supplemental content, including peer and mentor feedback through recorded and archived virtual learning. The TELI model also includes the tools needed for developing youthadult partnerships, which often provide positive developmental experiences for teens (Anderson \& Sandmann, 2009). Overall, the experiences provided through TELI aim to intertwine personal leadership skills and philosophies, which provide teens with a holistic consideration of their role as leaders and community advocates.

The TELI model has four overarching goals:

1. To understand self and develop a personalized action plan for engaged leadership.

2. To network with other teens interested in learning about the issues facing youth and communities.

3. To design a team project to address community leadership needs in Virginia.

4. To learn more about advocacy and outreach that will improve the lives of others

With these goals as a framework, we developed a four-component TELI model, including: understanding of self, developing a network, advocacy, and community problem solving (Figure 1). The integration of Chickering's Theory of Identity Development and the 4-H Citizenship Framework encompasses the goals incorporated through the 


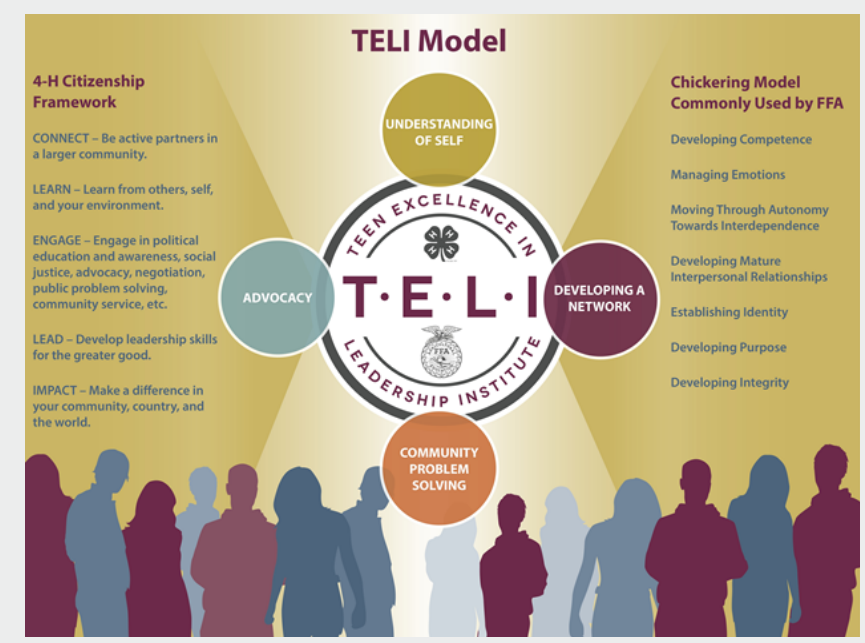

Figure 1. Complex Problem Conceptual Learning Framework.

TELI model components. Chickering's (1993) Theory of Identity Development-commonly utilized in FFA-provided guidance for promotion of the seven vectors: developing competence, managing emotions, moving through autonomy toward interdependence, developing mature interpersonal relationships, establishing identity, developing purpose, and developing integrity. Several previous studies made parallels between leadership education and Chickering's Theory of Identity Development (Buschlen \& Dvorak, 2011; Komives, Longerbeam, Owen, Mainella, \& Osteen, 2006; Owen, 2012).

The TELI model utilizes the 4-H Citizenship Framework by incorporating the key focus areas of civic engagement, service, civic education, and personal development (4-H National Headquarters, 2011). This framework is widely used in $4-\mathrm{H}$ programs throughout the country. Lerner, Lerner, and Colleagues (2013) revealed $4-\mathrm{H}$ members were twice as likely to be engaged in their communities and four times more likely to contribute to society. The 4- $\mathrm{H}$ Citizenship Framework and Chickering's Theory of Identity Development, intertwined, provided a solid foundation for youth-leadership development and the guidance needed to create the TELI model.

\section{Understanding of Self}

Goal one of TELI is for teens to develop an understanding of self and a personalized action plan for engaged leadership. To be a successful leader, it is essential that individuals understand themselves and how they interact with others. Authentic leaders develop their sense of self through a meaning system, which reinforces self-reflection on life stories (Shamir \& Eilam, 2005). Individuals partake in authentic leadership practices through the development of self-concept, clarity of values and beliefs, goals focused on self-concept, and heightened self-expressive behavior (Shamir \& Eilam, 2005). Therefore, developing a sense of self is one of the first steps in learning how to lead others.

The TELI model utilizes both learn and lead constructs from the 4-H Citizenship Framework (4-H National Headquarters, 2011). Activities are incorporated within the model to aid participants in the self-discovery process to find their own voice. Additionally, the model is constructed to incorporate the development of intellectual competence, emotional awareness, self-regulation, self-sufficiency, and identity formation (Chickering, 1993). Chickering (1993) supports self-chosen goals and autonomy as opportunities to move towards the development of integrity. To achieve this goal, TELI incorporates self-assessments, strengths training, and the development of a personalized action plan for engaged leadership, as activities for promoting understanding of self. 


\section{Developing a Network}

The second goal is built around the premise of allowing teens to build a peer community of practice (CoP). "Communities of practice are groups of people who share a concern or a passion for something they do and learn how to do it better as they interact regularly" (Wenger, 2011, p. 1). This goal fosters networking with other teens interested in learning about issues facing youth and communities. To build this network or CoP, sessions include social time, reflection, self-marketing, etiquette training, social media insight, and other networking activities. The 4-H Citizenship Framework reaffirms connect, learn, and engage as essential principles (4-H National Headquarters, 2011). Building a network provides an opportunity for youth to identify their connection in the larger community and to learn from others to appreciate diversity. The program also aims to develop interpersonal competence, emotional independence, and mature relationships (Chickering, 1993). By building trust slowly over the first weekend, a safe, supportive, and non-judgmental environment is provided for participants to be vulnerable with indepth sharing during reflection.

\section{Community Problem Solving}

With every problem solution comes unintended outcomes that consequently produce more problems (Friedel, 2014). These consequences ultimately fuse to create wicked problems. A wicked problem is a complex one that cannot be removed from its environment, and any solution will have positive and adverse impacts on the environment (Grint, 2005). With this in mind, wicked problems require a diverse team to examine solutions from multiple lenses. When driving change focused around wicked problems, community change agents must work in teams to identify the core issues and viable solutions. Goal three of TELI aims to heighten participants problem-solving skills by challenging youth to select and develop an intervention for a community-based wicked problem.

The third goal is for participants to design a team project to address community leadership needs in Virginia. Connect, engage, and impact are core concepts within the 4- $\mathrm{H}$ Citizenship Framework that encompass this goal (4-H National Headquarters, 2011). The TELI model challenges youth to begin finding their role in engaged community problem solving to make an impact through change within their local community, country, and world. As youth move through the seven vectors, they begin to develop competence for functioning as a team and instrumental independence for problem solving (Chickering, 1993). Further, individuals develop purpose and integrity by investing their core values and beliefs in the decision-making process. Teambuilding exercises, group-facilitation training, and mentored team-based projects encourage collaboration towards a team-developed solution to a community issue.

\section{Advocacy}

Goal four is for teens to learn more about advocacy and outreach to improve the lives of others. Promoting youth advocacy builds future leaders who are civic-minded and actively engaged in their communities (Villarruel et al., 2003). Community youth development overlays community development and PYD to engage youth in their communities. The TELI model utilizes the team-based problem to engage youth in their communities as they collect information on their issue. In addition, legislative advocacy, leadership in practice, and community service topics are encompassed to promote advocacy and future outreach efforts. When youth engage, lead, and impact, they focus on making their communities better through engaged citizenship (4-H National Headquarters, 2011). The TELI model aims for participants to see how they could make a difference in their community, which aids in the development of integrity through humanizing values (Chickering, 1993). The core of this goal is to develop a group of young change agents to serve as a voice for the future. 


\section{Evaluation Methodology}

We designed an evaluation to determine the overall effectiveness of TELI, highlight areas for development and improvement, and provide a proof of concept for the TELI model. The evaluation offered a means to convey feedback on the program to multiple stakeholders, including both public and private funders. We utilized select 4-H Citizenship Common Measures-aligned with program goals and the model-to determine participant growth and development. In addition to the quantitative measures, we incorporated focus groups with cohort two. Qualitative data provided further insight into program goals and participant feedback on the overall program design and activities.

Through applying both qualitative and quantitative methods, the design increases value by capitalizing on the strengths of each individual method (Curry, Nembhard, \& Bradley, 2009). Using both methods is a way of thinking with a complex and interdisciplinary mindset (Greene, 2007). Therefore, an evaluative research design with quantitative survey measures and qualitative focus group data provides a robust evaluation of TELI to determine alignment with program goals and the overall effectiveness of the program.

\section{Sampling Frame}

The population for this study included all participants in cohorts one and two of TELI $(\mathrm{N}=38)$. TELI participants are invited to take part in the program through a nomination and application process. All participants are current members of $4-\mathrm{H}$ clubs and/ or FFA organizations and between 15 to 18 years of age. We conducted a retrospective pretest and posttest on select 4-H Citizenship Common Measures with both cohorts $(\mathrm{N}=38)$. Out of the 38 possible participants, 12 participants from cohort one $(n=12)$ and 14 participants from cohort two $(n=14)$ consented to be participants and completed all questions on the 4-H Citizenship Common Measures instrument. Additionally, participants from cohort two partook in focus groups. Out of 18 possible participants, 14 individuals $(\mathrm{N}=18, \mathrm{n}=14)$ completed consent forms and participated in a focus group. The demographic information of the sample is unknown. However, demographic information is available for all 38 participants in cohorts one and two of TELI.

\section{Demographic Profile of TELI Participants}

The following provides explanation regarding the demographic characteristics of the 38 teens $(\mathrm{N}=38)$ that participated in cohorts one and two of TELI.

Gender, ethnicity, and race. Fifty-three percent $(n=20)$ of participants were female and $47 \% \quad(n=18)$ were male. In terms of ethnicity and race, 97\% identified themselves as non-Hispanic or Latino $(n=37)$. Eighty-seven percent $(n=33)$ of participants were white, $10 \%(n=4)$ were black or African American, and one respondent self-identified as Asian (3\%).

Program affiliation and residency. Of the 38 TELI participants, $42 \%(n=16)$ were members of $4-H, 37 \%$ $(n=14)$ were members of FFA, and $21 \%(n=8)$ were members of both organizations. The participants were dispersed throughout Virginia with $42 \% \quad(n=16)$ residing in Northern Virginia, 26\% $(\mathrm{n}=10)$ residing in Southeast Virginia, $16 \%(n=6)$ residing in Central Virginia, and $16 \%(n=6)$ residing in Southwest Virginia.

Quantitative Methods

To allow data-driven programming decisions and impact reporting, we utilized the National 4- $\mathrm{H}$ Citizenship Common Measures 1.0 to access the impacts of TELI in the areas of civic engagement, service, civic education, and personal development (4-H National Headquarters, 2011). In an effort to understand outcomes in the areas of understanding of self, developing a network, community problem solving, and advocacy, we designed a retrospective pre/post survey that incorporated questions from the 4- $\mathrm{H}$ Citizenship Common Measures matched to model components to identify the knowledge and confidence gained in relation. In accordance with program goals, we selected $164-\mathrm{H}$ Citizenship Common Measures to provide insight on program goals and the model. Participants responded to the 
16 4-H Citizenship Common Measures measured on a four-point Likert scale ( $4=$ very confident, $3=$ confident, $2=$ somewhat confident, and $1=$ not confident). We assigned each of the 16 4-H Citizenship Common Measures to a model component to create model constructs: understanding of self (three measures), developing a network (three measures), community problem solving (six measures), and advocacy

Table 1.

Program Goals Associated with 4-H Citizenship Common Measure Items and Input Activities. (four measures). An error by the research team resulted in two evaluation questions being omitted inadvertently during data collection with cohort two, which resulted in having responses to $144-\mathrm{H}$ Citizenship Common Measure questions. Table 1 provides an outline of the model and program goals in relation to inputs and the 4-H Citizenship Common Measures utilized in the study.

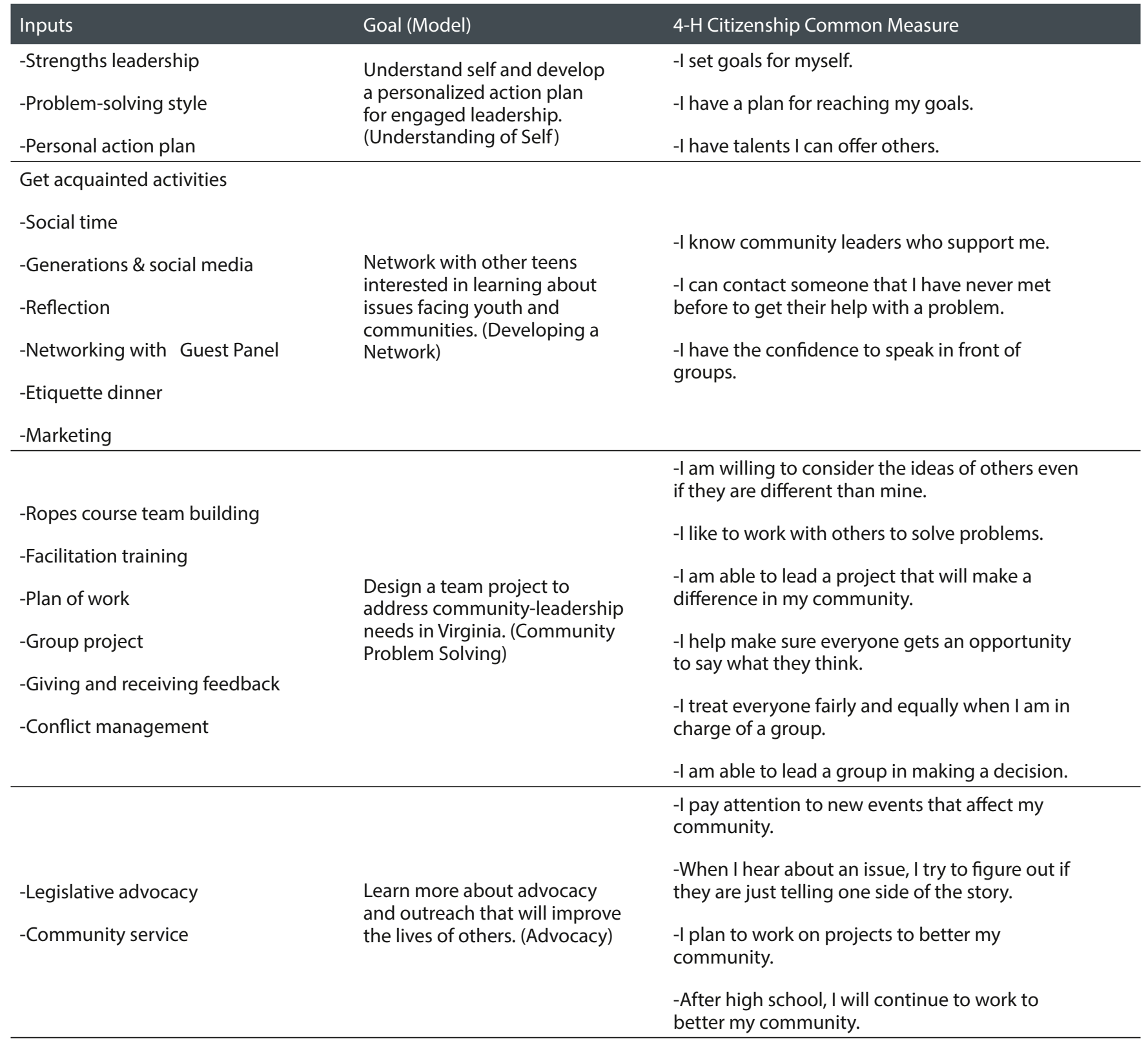

* Note. Inputs represent activities from cohort two. Some of the inputs varied between cohort one and cohort two. 
Data collection. Data collection occurred on the last day of the final face-to-face session. All 38 participants completed the evaluation, but only data from those with the appropriate signed consent forms and those who completed the survey in its entirety took part in this study. We used the current version of Qualtrics (2015) for data collection with cohort one $(n=12)$ and version 3.2 of the Plickers App (2016) for cohort two $(n=14)$.

With the first cohort, each participant used an iPad to capture their responses to the Qualtrics survey, which took approximately 20 minutes to complete. For cohort two, we utilized the Plickers App, which provided instant feedback regarding each evaluation question. Each participant received a unique and non-identifying "paper card"—which resembled a QR code. Participants held their "paper card" a certain way to indicate their choice on the Likert scale. The Plickers App posed a limitation in data collection because several participants' responses did not register when the $\mathrm{QR}$ code was scanned. This resulted in several participants with signed consent forms responses not being recorded for analysis.

Data analysis. We used SPSS version 24.0.0.0 to conduct significance testing with responses on the $4-\mathrm{H}$ Citizenship Common Measures. We analyzed cohort one and cohort two data separately and comparisons were not made between data or group data. We employed a Wilcoxon signed-rank test to determine whether there were significant differences between means on retrospective pretests and posttests for each construct: understanding of self, developing a network, community problem solving, and advocacy. A Wilcoxon signed-rank test is a nonparametric test, which does not assume normality with distribution (Woolson, 2008). Wilcoxon signed-rank test examines intrapair differences between each individual for overall significant changes and is appropriate for small sample sizes (Woolson, 2008).

\section{Qualitative Methods}

To achieve more in-depth feedback from participants ( $n=14$ ) about the TELI experience, we conducted focus groups with the second cohort. On site at the second (final) face-to-face session, we randomly assigned participants to one of two focus groups with seven participants in each focus group. Two researchers conducted the focus groups while two additional researchers served as notetakers. We conducted the focus groups using a protocol approved by the university Institutional Review Board and each one lasted 35-40 minutes. The focus group protocol included questions around the following topics: meaningful experiences, least meaningful activities, learned skills, how skills will be applied in the future, and recommendations for changes to the program. We transcribed all audio files verbatim.

Data analysis. We utilized an iterative process to increase trustworthiness throughout the coding and meaning making process (Creswell, 2013). Five researchers independently coded transcripts for comparison and inter-coder reliability (Creswell, 1998). Then, collaboratively, we discussed and compared the codes related to meaning units of data to increase inter-coder reliability as well as discussed patterns for consensus on emergent themes (Creswell, 1998).

Researcher reflexivity. Within qualitative research, reflexivity is an important element to disclose how biases, values, and background of the researchers shape the study and results (Creswell, 2013). To increase the credibility, trustworthiness, and authenticity of the researchers, the following reflexivity statement was prepared:

The five researchers serving as the leadership team for the program and were instrumental in the development of the program and model. Four of the five team members work with Virginia Extension programs; two of the researchers work with $4-\mathrm{H}$ at the state level, one worked with Extension fund development and is a past FFA state officer, and one researcher has close ties to both FFA and $4-\mathrm{H}$ and currently serves as the director for the adult leadership program in agriculture at Virginia Tech. The final researcher was a PhD student with previous experience 
with 4-H and a focus on teen-leadership development.

The researchers recognize that the diversity of experiences represented in the team provide a wellrounded perspective and recognized biases of the team may or may not affect the interpretation of the impact of the program. Throughout the development and evaluation of the program, the team challenged each other to consider multiple perspectives and continually monitored biases.

\section{Results}

Quantitative Results

At the final weekend session for each cohort, participants completed surveys to indicate their confidence on selected $4-\mathrm{H}$ Citizenship Common Measures using a four-point Likert scale. Participants reflected on their confidence before TELI and after ( $1=$ not confident, $2=$ somewhat confident, $3=$ confident and $4=$ very confident). We chose the 4-H Citizenship Common Measures to begin uniform data collection suitable for ongoing studies and sharing with youth practitioners. We could not assume the data was normally distributed given the small number of respondents, thus we used Wilcoxon signed-rank tests to examine whether statistical differences existed between the change in means for pre- and post-survey results for each construct (Woolson, 2008). In both year one and year two, respondents indicated a statistically significant change for each of the four constructs.

Table 2.

Means of 4-H Common Measures for Before and After TELI and Significance from Wilcoxon Signed Ranks

\begin{tabular}{lccccccc}
\hline \multirow{2}{*}{ Construct } & \multicolumn{3}{c}{ Cohort One $(n=12)$} & \multicolumn{3}{c}{ Cohort Two $(n=14)$} \\
\cline { 2 - 7 } & $\mathrm{Z}$ & $p$ & $\mathrm{Si}$ & $\mathrm{Z}$ & $p$ & Sig. \\
\hline Understanding of self & - & .002 & $*$ & -2.585 & .010 & $*$ \\
Developing a network & - & .003 & $*$ & -2.992 & .003 & $*$ \\
Community problem solving & - & .001 & $*$ & -3.192 & .001 & $*$ \\
Advocacy & - & .003 & $*$ & -3.240 & .001 & $*$ \\
\hline
\end{tabular}

${ }^{* *} \mathrm{p}<.05$. Constructs were evaluated using a four-point Likert scale $(4=$ very confident, $3=$ confident, $2=$ somewhat confident, and $1=$ not confident).

\section{Qualitative Results}

Qualitative data analysis of the focus group responses $(n=14)$ included the identification of salient themes and sub-themes for each response. There were two overall types of responses to focus group questions: program improvement and program outcome. For the purpose of this study, we did not report program improvement responses related to process evaluation and program operation including logistics, location, and delivery mode. Program outcome responses included data related to impact, effectiveness, and skill development as result of implementing the TELI model. The themes identified (Figure 2) are those that emerged from the program outcome category and are overall experiences that participants reported from partaking in TELI. The major themes identified were: diversity, learning about self, skill development, connection, and practical application.

Diversity

Interacting and working with others from a wide variety of backgrounds including geographic regions, interests, and abilities was a common experience among TELI participants. 


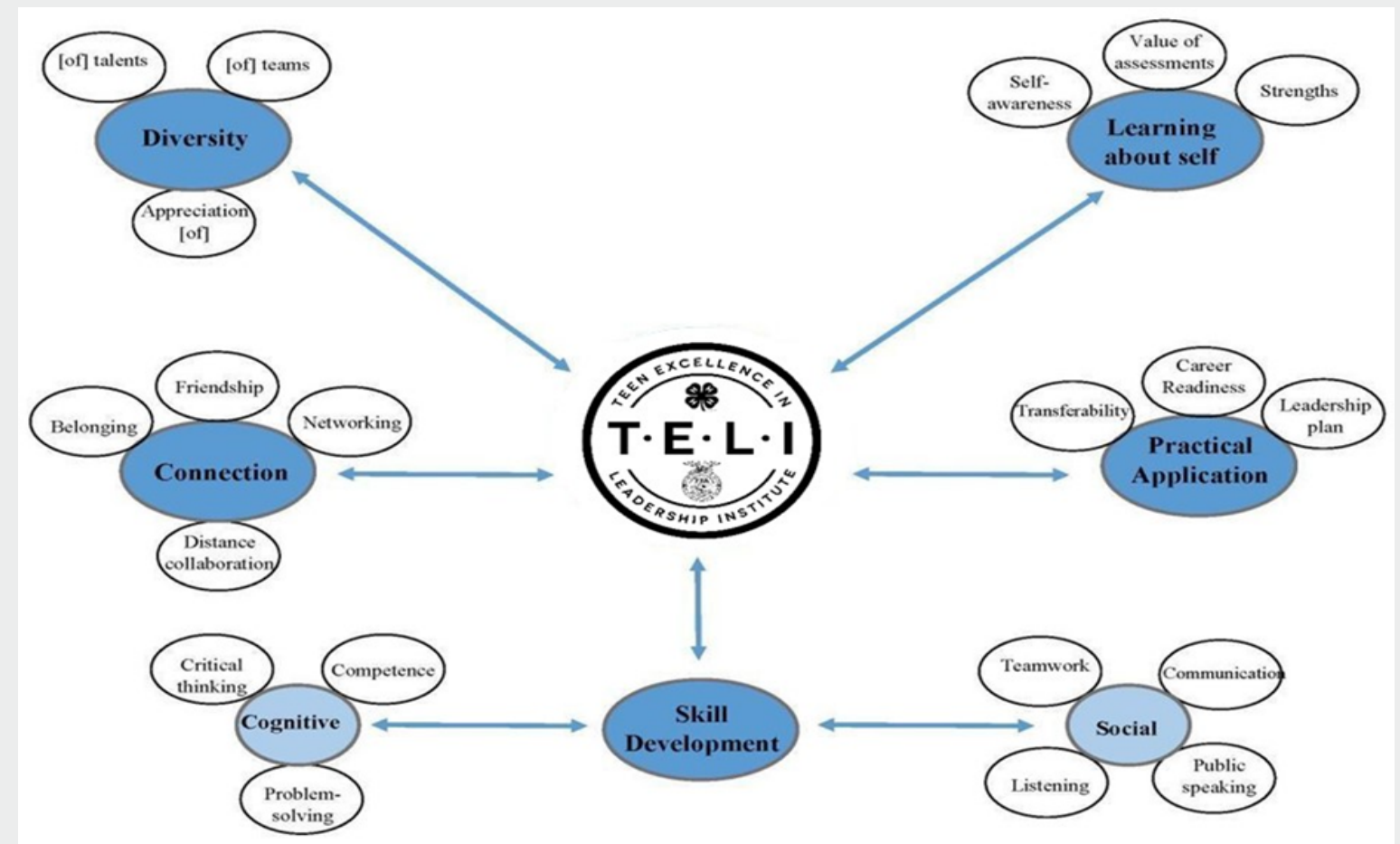

Figure 2. Graphic element of the salient themes and sub-themes of focus group responses..

Participants recognized diversity of skills and abilities within their teams. One participant shared, "Learning to work with people you've never worked with before. Umm, like different types of people, whether you're innovative or adaptive or just learning how to communicate with people who are different from you." One teen communicated an appreciation of how the variety of talents of members supported the team in making progress toward a goal:

... if your team is very similar, you're kind of all on the same track, and I think it can make progress slower. But, I think being able to have a diversified team allows each person to take different roles and be able to get their work done in more of a timely manner than having everyone work on the same role. Umm, to try and get an overall product done.

\section{Learning About Self}

The use of self-assessments allowed participants to reflect and develop an awareness of preferences for problem solving and individual strengths. One participant explained how identification of personal strengths was threaded throughout the entire TELI program and served as a foundation to build additional leadership skills,

I learned a lot more about the strengths, like with the KAI test and everything, I learned a lot more about that than what I thought was going to be provided. I thought we were just going to get those and talk about it and that be it. But it kind of overlapped with everything we did.

\section{One teen shared the connection between} preference for problem solving and structure within educational delivery:

Uhh, I think working with the other leaders of my class and also like my KAI score kind of explained why I like certain classes better than others based off the 
syllabus and the type of assignments you do with structure or without. So that kind of helped me understand more about my learning style, as well.

\section{Connection}

The TELI experience created an environment to foster a sense of belonging, connection, and opportunities to develop networking and friendship. Although the program delivery is time-specific, participants recognize connections made, as expressed by one individual and echoed by others:

And even though we were here for TELI and to learn how we can apply our own skills to a service and ourselves we have connections with each other and being from two different organizations, we may not see each other again.

Further, the program delivery format fostered a comfortable environment for participants to connect, exemplified when one participant stated, "It was a really comfortable environment to like feel like you can interact with everyone. And so, as far as interacting that's just another experience that I was able to have."

\section{Practical Application}

The teens identified ways skills learned in TELI could be applied to various settings in the future. Specific examples of how the skills developed through the program could be transferred to other team experiences is highlighted in this participant's description, "Yeah, I've used them [skills] in my FFA chapter as Vice President, President next year and really trying to get out there and work with the officer team well and other members in the chapter."

One participant anticipated the skills to be useful in the future and to prepare them for college and the workforce as stated in the following response, "I thought finding my strengths were the most meaningful because that can help you well into your future. Finding a job path that you like and a degree, college, you know stuff like that."
Skill Development

TELI participants identified increased confidence and competence in the development of cognitive and social skills. Identified cognitive skills included critical thinking and problem solving. Social skills included communication, teamwork, public speaking, and listening. Cognitive skills are those that engage the participant in the acquisition of new knowledge or competence such as critical thinking and problem solving. Teens felt they gained a specific strategy for navigating the program planning process. One teen articulated:

As we were sort of putting the things together for our presentation, we were thinking about the order of how we should apply everything. Starting with the why and the purpose of what we were doing is something pretty big of how we started to present. Because when you're trying to catch the, umm, audience's attention, you want to say this is the purpose and how it leads exactly into what you're doing. So that was something I suppose the golden circle and the facilitation that we were learning that we could apply.

Social skills are those that foster connection and build relationships with others, as exemplified below:

I think learning to work with other people. Skills where you're weak definitely helps because we don't all have the same skills and that really helped form the teams better cause if someone's going to communicate, but someone is better at problem solving then it fits together better rather than having two people that are really good at communicating and one weak at problem solving.

\section{Discussion and Conclusions}

After a successful inaugural program in 2014, we replicated TELI each subsequent year, reaching 73 
teens between four cohorts combined. Evaluations provided information for program adjustments and improvement following each year. For example, we adjusted and condensed the time frame of the program based on feedback stating there was too much time between the first face-to-face weekend and the last. Overall, the we conclude that evaluation data provided support for TELI's effectiveness in increasing knowledge and skills related to understanding of self, developing a network, community problem solving, and advocacy. Concurring with the findings of Seevers and Dormody (1994a, 1994b), involving both 4-H and FFA youth in higher level leadership opportunities, beyond their locality, is beneficial.

Furthermore, findings from this program evaluation contribute to the field of research on youth development by providing challenging activities to youth that encourage teamwork and personal development (Roth \& Brooks-Gunn, 2015; Akiva, Cortina, Eccles, \& Smith, 2013; Salusky et al., 2014). There is now data supporting the TELI model and highlighting the experiences TELI participants gain in regards to leadership development and how they have applied their acquired knowledge in becoming community leaders. Most of the skills learned by participants map back to the educational content of the program-Chickering's (1993) Theory of Identity Development amd the 4-H Citizenship Framework (4-H National Headquarters, 2011) — upon which the program model was developed.

Participants self-reported that skills such as critical thinking, problem solving, teamwork, and public speaking will be useful in their continued community work as well as in other facets of their lives.

Furthermore, these findings concur with previous research (Lerner et al., 2005) that by engaging youth in the Five Cs: competence, confidence, character, connection, and caring of PYD, attitudes towards civic endeavors increase positively. Additionally, this study supports the research of Hastings, Barrett, Barbuto, and Bell (2011) who found that providing "real world", out of school experiences contribute to youth-leadership development. Second, since the program was inclusive of both 4-H and FFA youth, the researchers concluded that TELI positively impacts participating youth, regardless of program affiliation.

Results from this program can be useful to youth practitioners focusing on PYD and growth of the Five Cs when delivering the TELI model. Finally, findings from the 4-H Citizenship Common Measures corroborate observed growth in each aim of the program and support the model. Focus group discussions provided additional examples of TELI graduates being better prepared for leadership roles along five salient themes: learning of self, diversity, connection, practical application, and skill development. Findings from this program evaluation serve as a foundation to further promote and accomplish the goals of the Virginia 4- $\mathrm{H}$ and FFA youth-leadership programs in impactful ways. However, it is also understood that the leadership development reported by an individual cannot be attributed to TELI alone, nor to any extracurricular activity (Theokas, Lerner, Phelps, \& Lerner, 2006).

\section{Recommendations}

As a recommendation for future research, continued evaluation of the program and similar programs should be conducted. These evaluations should continue to aim to verify the TELI model and provide information for continued program improvement. For TELI, adjustments should be made to the evaluation methods to incorporate a mixed methods design with the opportunity to integrate both quantitative and qualitative data. Further, several previous studies reported skill development as a primary outcome of their youth leadership-development programs, corroborated as a finding within this study (Bean, Harlow, Kendellen, 2017; Kress, 2006; Reichard et al., 2011). The researchers recommend inquiry in youth-leadership development aimed further than skill development to examine long-term outcomes, including application and transferability of leadership growth. Additionally, graduates of the TELI program should 
be reassessed for long-term change overtime.

Understanding how participants benefitted from

the program after a length of time away from the

program would provide further implications for the

program and model's usefulness.

From a practitioner's perspective, other states

should consider developing and implementing

advanced youth-leadership training. The researchers

have intentions to produce a handbook for program

implementation and replication within other states.

By providing further insight into the program design

and activities associated with each portion of the

TELI model, other states and programs will be able

to adapt the program for usage within their state or

with other populations.

Finally, it is recommended that practitioners looking to develop their own youth-leadership programs utilize proven theory and practices throughout the development process. Intentionality within this development is crucial and aids in building a program with predicted success (Klau, 2006; Redmond \& Dolan, 2016). Exemplary programs include "the deliberate teaching of learning opportunities or life skills within a program- paired with strategic decisions to create opportunities that maximize developmental outcomes" (Bean et al., 2017, p. 76). Within the development of TELI, knowledge and theories were utilized to maximize activities for optimal growth. Thus, it is recommended that other youth-leadership programs utilize solid theoretical and practical foundations for success. 


\section{References}

4-H National Headquarters. (2011). 4-H citizenship program. Washington, DC. Swanson, D.

Akiva, T., Cortina, K. S., Eccles, J. S., \& Smith, C. (2013). Youth belonging and cognitive engagement in organized activities: A large-scale field study. Journal of Applied Developmental Psychology, 34(5), 208218.

Andenoro, A. C., Allen, S. J., Haber-Curran, P., Jenkins, D. M., Sowcik, M., Dugan, J. P., Osteen, L. (2013). National Leadership Education research agenda. 2013-2018: Providing strategic direction for the field of leadership education. Retrieved from Association of Leadership Educators website: http:// leadershipeducators.org/ResearchAgenda

Anderson, K. S., \& Sandmann, L. (2009). Toward a model of empowering practices in youth-adult partnerships. Journal of Extension, 47(2), 1-8.

Bean, C., Harlow, M., \& Kendellen, K. (2017). Strategies for fostering basic psychological needs support in high quality youth leadership programs. Evaluation and Program Planning, 61, 76-85. doi: 10.1016/j. evalprogplan.2016.12.003

Buschlen, E., \& Dvorak, R. (2011). The social change model as pedagogy: Examining undergraduate leadership growth. Journal of Leadership Education, 10(2), 38-56.

Chickering, A. (1993). The seven vectors: An overview. Education and Identity, 43-52.

Crawford, P., Lang, S., Fink, W., Dalton R., \& Fielitz L. (2011). Comparative analysis of soft skills: What is important for new graduates? Washington, DC: Association of Public Land-grant Universities.

Creswell, J. W. (1998). Qualitative inquiry and research design. Thousand Oaks, CA: Sage Publications.

Creswell, J.W. (2013). Research design: Qualitative, quantitative, and mixed methods approach. Los Angeles, CA: Sage Publications.

Curry, L. A., Nembhard, I. M., \& Bradley, E. H. (2009). Qualitative and mixed methods provide unique contributions to outcomes research. Circulation, 119(10), 1442-1452. doi: 10.1161/ CIRCULATIONAHA $>107.742775$

Damon, W. (2004). What is positive youth development? The Annals of the American Academy of Political and Social Science, 591, 13-24. Retrieved from http://www.jstor.org/stable/4127632

Friedel, C. (2014). The value of adaption and innovation as a function of diversity. In N. Erbe (Ed.) Approaches to managing organizational diversity and innovation (pp. 63-81). Hershey, PA: IGI Global. Retrieved from http://www.igi-global.com/chapter/the-value-ofadaption-and-innovation-as-a-function-ofdiversity/108471

Gestsdóttir, S., \& Lerner, R. M. (2007). Intentional self-regulation and positive youth development in early adolescence: Findings from the 4-H study of positive youth development. Developmental Psychology, 43(2), 508. doi: 10.1037/0012-1649.43.2.508

Greene, J. C. (2007). Mixed methods in social inquiry. San Francisco, CA: Jossey-Bass. 


\section{References}

Grint, K. (2005). Problems, problems, problems: The social construct of 'leadership'. Human Relations, 58(11), 1467-1494. doi: 10.1177/0018726705061314

Hastings, L. J., Barrett, L. A., Barbuto Jr, J. E., \& Bell, L. C. (2011). Developing a paradigm model of youth leadership development and community engagement: A grounded theory. Journal of Agricultural Education, 52(1), 19-29. doi: 10.5032/jae.2011.01019

IBM Corp. (2016). SPSS (Version 24.0.0.0) [Software]. Armonk, NY: IBM Corp.

Jelicic, H., Bobek, D. L., Phelps, E., Lerner, R. M., \& Lerner, J. V. (2007). Using positive youth development to predict contribution and risk behaviors in early adolescence: Findings from the first two waves of the 4-H Study of positive youth development. International Journal of Behavioral Development, 31(3), 263-273. doi:10.1177/0165025407076439

Klau, M. (2006). Exploring youth leadership in theory and practice. New Directions for Student Leadership, 2006(109), 57-87. doi:10.1002/yd.155

Komives, S. R., Longerbeam, S. D., Owen, J. E., Mainella, F. C., \& Osteen, L. (2006). A leadership identity development model: Applications from a grounded theory. Journal of College Student Development, 47(4), 401-418.

Larson, R. W. (2000). Toward a psychology of positive youth development. American Psychologist, 55(1), 170183. doi:10.1037//0003-066X..55.1.170

Larson, R. (2006). Positive youth development, willful adolescents, and mentoring. Journal of Community Psychology, 34(6), 677-689.

Lerner, R. M., Almerigi, J. B., Theokas, C., \& Lerner, J. V. (2005). Positive youth development a view of the issues. The Journal of Early Adolescence, 25(1), 10-16. doi: 10.1177/0272431604273211

Lerner, R. M., Dowling, E. M., \& Anderson, P. M. (2003). Positive youth development: Thriving as the basis of personhood and civil society. Applied Developmental Science, 7(3), 172-180. doi:10.1207/ S1532480XADS0703_8

Lerner, M. L., Lerner, J. V., \& Colleagues. (2013). The positive development of youth: Comprehensive findings from the 4-H study of positive youth development. Retrieved from http://3t61 of 1t6u3x3af7ir2y91ib. wpengine.netdna-cdn.com/wp-content/uploads/2016/02/4-H-Study-of-Positive-Youth-Development-FullReport.pdf

Lerner, R.M., Lerner, J.V., \& Colleagues. (2008). The positive development of youth: Report of the findings from the first seven years of the 4-H study of positive youth development. Medford, MA: Institute for Applied Research in Youth Development. Retrieved from https://ase.tufts.edu/iaryd/ documents/4HPYDStudyWave7.pdf

Owen, J. E. (2012). Using student development theories as conceptual frameworks in leadership education. New Directions for Student Services, 2012(140), 17-35. doi:10.1002/ss.20029 


\section{References}

Perkins, D. F., Borden, L. M., Keith, J. G., Hoppe-Rooney, T. L., \& Villarruel, F. A. (2003). Community youth development. In Villarruel, F. A., Perkins, D. F., Borden, L. M., \& Keith, J. G., Community youth development: Programs, policies, and practices, (pp.1-23). Thousand Oaks, CA: Sage Publications.

Plickers Inc [Application software]. (2016). South San Francisco, CA: Plickers Inc.

Qualtrics. (n.d.). Qualtrics [Software]. Provo, UT: Qualtrics.

Radhakrishna, R. B., \& Sinasky, M. (2005). 4-H experiences contributing to leadership and personal development of 4-H alumni. Journal of Extension, 43(6).

Ricketts, J.C., \& Rudd, R. D. (2002). A comprehensive leadership education model to train, teach, and develop leadership in youth. Retrieved from http://scholar.lib.vt.edu/ejournals/JCTE/v19n1/ricketts.html

Roth, J. L., \& Brooks-Gunn, J. (2003). What exactly is a youth development program? Answers from research and practice. Applied Developmental Science, 7(2), 94-111. doi: 10.1207/S1532480XADS0702_6

Rutherford, T.A., Stedman, N., Felton, S., Wingenbach, G., \& Harlin, J. (2004). Developing skills for the future: Graduates' perceptions of career skill preparedness and importance after a four-year undergraduate program. Retrieved from http://aaaeonline.org/uploads/ allconferences/papers/h-3.pdf

Salusky, I., Larson, R.W, Griffith, A., Wu, J., Raffaelli, M., Sugimura, N. \& Guzman, M. (2014). How adolescents develop responsibility: What can be learned from youth programs. Journal of Research on Adolescence, 24(3), 417-430.

Seevers, B.S., \& Dormody, T.J. (1994a). Predicting youth leadership skills development among senior 4-H members: A tri-state study. Journal of Agricultural Education, 35(3), 64-69.

Seevers, B.S., \& Dormody, T.J. (1994b). 4-H youth participation in leadership development activities: A tristate study. Journal of Agricultural Education, 35(4), 49-54.

Shamir, B., \& Eilam, G. (2005). "What's your story?" A life-stories approach to authentic leadership development. The Leadership Quarterly, 16(3), 395-417. doi:10.1016/j.leaqua.2005.03.005

Shek, D. T., \& Sun, R. C. (2015). Positive youth development (PYD) and adolescent development: reflection on related research findings and programs. In Student Well-Being in Chinese Adolescents in Hong Kong (pp. 325-337). Singapore: Springer. doi:10.1007/978-981-287-582-2_24

Theokas, C., Lerner, J.V., Phelps, E., \& Lerner, R.M. (2006). Cacophony and change in youth after school activities: Findings from the 4-H study of positive youth development, Journal of Youth Development, 1(1). Retrieved from http://www.uwex.edu/ces/4h/ educators/documents/Theokasetal.JYD12006. pdf40408d2250c\%40sessionmgr12

Townsend, C.D., \& Carter, R.I. (1983). The relationship of participation in FFA activities and leadership, citizenship, and cooperation. AATEA Journal, 24(I): 20-25.

Villarruel, F. A., Perkins, D. F., Borden, L. M., \& Keith, J. G. (2003). Community youth development: Programs, policies, and practices. Thousand Oaks, CA: Sage Publications. 


\section{References}

Wenger, E. (2011). Communities of practice: A brief introduction. Retrieved from https://scholarsbank. uoregon.edu/xmlui/bitstream/handle/1794/11736/A\%20brief\%20intr oduction\%20to\%20CoP. pdf?sequence $=1$ \&isAllowed $=y$

Woolson, R. F. (2008). Wilcoxon signed-rank test. Wiley Encyclopedia of Clinical Trials. doi:10.1002/9780471462422

Worker, S. M. (2014). Evaluating adolescent satisfaction of a 4-H leadership development conference. Journal of Extension, 54(2).

Zimmerman, B. J., \& Cleary, T. J. (2006). Adolescents' development of personal agency: The role of selfefficacy beliefs and self-regulatory skill. In F. Pajares \& T. Urdan (Eds.), Self-efficacy beliefs of adolescents (pp. 45-66). Greenwich, CT: Information Age Publishing. 